\title{
A PRODUÇÃO DO ESPAÇO PÚBLICO: DA DOMINAÇÃO À APROPRIAÇÃO*
}

\author{
Oscar Sobarzo**
}

\section{RESUMO:}

Propomos uma análise dos espaços públicos na perspectiva da produção do espaço, que relaciona os campos da dominação e da apropriação a partir da leitura da dominação política, da acumulação de capital e da realização da vida. A dominação política remete-nos ao papel do poder político e das elites na produção do espaço público; a acumulação de capital, ao surgimento de novos produtos imobiliários que aumentam a reprodução e a circulação do capital e questionam a relação do público e do privado; e, finalmente, a esfera da realização da vida humana materializa-se nos espaços públicos que possibilitam as práticas cotidianas. A partir do cotidiano muda o foco das análises dos espaços públicos da dominação para a apropriação, destacando a sua importância na produção de relações de identidade e pertencimento que permitem a leitura das possibilidades, da superação ou da subversão.

PALAVRAS-CHAVE:

Espaço público, produção do espaço, dominação, apropriação

\section{ABSTRACT:}

We propose an analysis of the public spaces through the point of view of the production of the space, that it relates the field activity of the dominance and of the appropriation. This approach is starting from the interpretation of the political dominance, of the capital accumulation and of the accomplishment of the people's life. The political dominance refers us to the role of the elite's political power in the production of the public space; also the capital accumulation, to the appearance of new products in the real estates market whose increase the reproduction and the circulation of the capital. This process question the relationship between what is public and private. Finally, it is discussing the sphere of the materialized human life realization in the public spaces which makes possible their daily practices. In that case, according to the quotidian there is changing the focus of the analyses of the public spaces of the dominance for appropriation, pointing out its importance in the production of people's identity and appurtenance that allow to do the check list of the possibilities to overcoming or to subverting this process.

\section{KEY WORDS:}

work force; city; industry; spatial segregation; appropriation

* Neste texto são reproduzidas reflexões desenvolvidas na tese de doutorado do autor titulada "Os espaços da sociabilidade segmentada: a produção do espaço público em Presidente Prudente", orientada pela professora Dra. Maria Encarnação Beltrão Sposito e defendida no Programa de

Pós-Graduação em Geografia da FCT/UNESP (campus de Presidente Prudente) em março de 2005. A pesquisa contou com o apoio da CAPES (Programa PEC/PG).

* Professor da Universidade Federal do Rio Grande do Sul. E-mail: sobarzo@ig.com.br 


\section{Introdução}

Começamos este artigo nos posicionando contrários à suposta morte do espaço público, mas alertando sobre a sua transformação. Falar em morte do espaço público nos parece simplista demais, já que esse posicionamento tende a se fechar em si mesmo, limitando as análises.

Mas, qual espaço público está em transformação? É fundamental ter presente que o espaço público atual é herdeiro da Modernidade e, como tal, assim como Caldeira (2000, p. 302-303) ressalta, carrega os traços do "ideal moderno da vida pública urbana": ruas abertas, circulação livre, encontros impessoais e anônimos, presença dos diferentes grupos sociais consumindo, observando-se, participando da política, divertindo-se etc. Segundo essa autora, os espaços públicos que estão sendo criados nas grandes metrópoles contemporâneas negam esse ideal e, ao contrário, assumem a desigualdade e a separação como valores estruturantes; entretanto, isso não significa a morte do espaço público, mas sim a transformação de um tipo de espaço para outro.

Um aspecto que nos parece fundamental para a análise da transformação do espaço público é a sua característica de possibilitador de encontros impessoais e anônimos e de copresença dos diferentes grupos sociais ${ }^{1}$. Tais encontros devem ser entendidos como a possibilidade de compartilhar os mesmos territórios com outras pessoas sem a compulsão para conhecê-las em profundidade. Assim, "o espaço público é o lugar das indiferenças, ou seja, onde as afinidades sociais, os jogos de prestígio, as diferenças, quaisquer que sejam, devem se submeter às regras da civilidade" (GOMES, 2002, p. 162).

Nesse sentido, partimos de uma perspectiva que assume a diferença no espaço público, mas que não idealiza o convívio entre a diversidade como se fosse uma relação próxima e profunda; pelo contrário, parte do pressuposto de que o ideal moderno era um convívio civilizado, sob normas impessoais.
Nesse sentido, a possibilidade de encontros "civilizados" pode ser entendida como a capacidade social, no espaço público, de se propiciar a reunião entre as diferenças, permitir a mútua observação, o diálogo e a co-presença, sem significar, embora muitas vezes tenha acontecido, a manifestação dos conflitos e interesses antagônicos.

A consideração desses elementos é muito importante para se evitarem idealizações extremas e simplistas, e para se oferecerem parâmetros para contextualizar o espaço público que hoje estamos transformando.

A abordagem analítica que propomos para o espaço público tem a sua base teóricometodológica na produção do espaço urbano a cidade como produto e condicionante da reprodução da sociedade, da reprodução da vida, das relações sociais que se manifestam na prática socioespacial, ou seja, o espaço construído e modificado, no dia-a-dia, nas ações cotidianas, no uso e na apropriação que dele se faz e, ao mesmo tempo, o espaço influenciando essa cotidianidade.

Nesse contexto, a nossa abordagem teórico-metodológica encontra fundamentais subsídios na obra de Henri Lefebvre, que superou a concepção tradicional do espaço como um receptáculo - o espaço é também nível de determinação - , e confrontou a sua suposta neutralidade com sua função instrumental, destacando a complexidade e as potencialidades do espaço, pois, na sua realidade atual, possui a possibilidade de um projeto diferente (LEFEBVRE, 1992).

Lefebvre considera o espaço como um produto - entendendo os conceitos de produto e produção no sentido amplo, filosófico -, mas não se trata de um produto como qualquer outro, nem um objeto, coisa, mercadoria ou a soma delas. Tampouco se trata de um instrumento, mas sim do mais importante dos instrumentos, o pressuposto de toda produção e de todo intercâmbio. O espaço está essencialmente vinculado com a reprodução das 
relações sociais de produção (LEFEBVRE, 1976, p. 34).

Nessa perspectiva, o espaço público é analisado como um produto e um possibilitador das relações sociais. Como já foi apontado, o espaço público não pode, nem deve ser, idealizado como um local de convívio próximo e profundo da diversidade. A sua concepção moderna colocava-o como um possibilitador de encontros impessoais e civilizados que obedeciam e respeitavam a lógica do próprio sistema, assumidamente desigual, pois lembremos que, entre as transformações da Modernidade, está o desenvolvimento do sistema capitalista, que se fundamenta na desigualdade.

O grau com que esses ideais do espaço público se materializaram na sociedade brasileira e se efetivaram em nossas cidades altera essa leitura. Se a nossa modernidade foi incompleta e híbrida (MARTINS, 1994; 2000), evidentemente não podemos pensar que o espaço público assumiu totalmente esses valores, mas mesmo assim não podem ser desconhecidas as possibilidades que os espaços públicos sempre ofereceram para o encontro, a fala, os olhares, os passos, a discussão, em resumo, para a sociabilidade.

Na perspectiva da produção do espaço, como reprodução das relações sociais por meio de práticas socioespaciais, a análise da cidade ganha em complexidade, enriquecendo-se em pontos de vista e perspectivas de abordagem. Com essa orientação metodológica, consideramos que os estudos urbanos adquirem um maior peso analítico.

Para avançar nessa perspectiva, incorporamos o enfoque de Ana Fani Alessandri Carlos (2001, p. 12) que propõe três níveis de análise para a produção do espaço - dominação política, acumulação do capital e realização da vida humana -, os quais podem ser claramente lidos no espaço público. A dominação política é analisada do ponto de vista das ações do poder municipal e das elites na produção dos espaços públicos e das indefinições que, nesse agir, se identificam na defesa dos interesses públicos e privados. A acumulação de capital é abordada pelo surgimento de novos produtos imobiliários que aumentam a reprodução e a circulação do capital, estimulando a obsolescência de antigas formas e conteúdos, apresentando a cidade ou parte dela na embalagem de um novo produto a ser comprado e/ou consumido, mas que também questionam diretamente a relação entre o público e o privado. Finalmente, a esfera da realização da vida materializa-se nos espaços públicos que possibilitam práticas cotidianas de lazer, de consumo, de circulação etc.

A realidade hoje nos impõe grandes questionamentos para a abordagem do espaço público. A consolidação de novos produtos imobiliários - loteamentos fechados, shopping centers, centros empresariais, parques temáticos, centros turísticos - questionam o significado do espaço público. Os novos espaços "públicos" - realmente semipúblicos ou pseudopúblicos - são muitas vezes caricaturas da vida social, negando ou ocultando as diferenças e os conflitos, tornando a sociabilidade mais "clean" e, em último termo, negando-a.

Para Carlos (2001, p. 36 e 353), essas transformações esvaziam o espaço público de seu sentido tradicional de lugar que possibilita as relações sociais, retirando e negando o acontecer do imprevisto, da improvisação, do espontâneo, da convivência, dos encontros, dos conflitos, das rotinas e dos desacordos. As relações sociais passam a ser mediadas por normas e organizadas em função do consumo, representando práticas de exclusão, pois os espaços são vigiados e controlados.

Contudo, neste texto pretendemos transitar da dominação - expressa na produção do espaço do ponto de vista político e econômico - para a apropriação - expressa na esfera da realização da vida -, com o intuito de destacar a importância do espaço público no cotidiano para a gestação das possibilidades e subversões. 
O caráter teórico das reflexões apresentadas tenta não esgotá-las nem limitálas num determinado recorte territorial, contudo - leitor perceberá em algumas análises uma preocupação de contextualização nas cidades médias, situação que se explica pelas características da pesquisa que originou este texto.

\section{I- A produção do espaço público e dominação política}

O espaço envolve o poder e o poder significa controle e dominação. Como aponta Lefebvre (1992, p. 349), o espaço possui a característica de ser "politicamente instrumental, facilitando, com isso, o controle da sociedade", mas essa dimensão tende a ser disfarçada, já que "assume uma aparência externa de neutralidade, de insignificância, de destituição semiológica e de vazio (ou ausência)".

A compreensão da relação entre o espaço e a dominação política e o poder no Brasil passa pelo entendimento do processo de constituição da propriedade da terra - privada e pública - no marco da transição do Brasil Colonial ao Brasil Republicano, em meados do século XIX. De fato, a institucionalização da propriedade nos padrões da Lei de Terras de 1850 transfere à terra, ao detentor da sua propriedade, poder, não somente econômico, mas também político.

Martins (1981) analisa esse processo no contexto da passagem de uma sociedade escravocrata para uma sociedade de trabalho livre. Na primeira, a terra não representava o patrimônio porque existia o direito à sua ocupação, mas não à sua propriedade; assim, o patrimônio estava determinado em função da propriedade de escravos. A transição para uma sociedade de trabalho livre exigiu que se assegurasse o patrimônio dos beneficiários de sesmarias, transferindo para a propriedade da terra essa condição. "A renda capitalizada no escravo transformava-se em renda territorial capitalizada: num regime de terras livres, o trabalho tinha que ser cativo; num regime de trabalho livre, a terra tinha que ser cativa" (MARTINS, 1981, p. 32).

A propriedade capitalista da terra permitiu o acesso ao sistema bancário, antes determinado pela propriedade de escravos, mas também "assegurava ao fazendeiro a sujeição do trabalho", visto que os trabalhadores livres - colonos imigrantes - deviam trabalhar nas fazendas antes de se transformarem em proprietários (MARTINS, 1981, p. 74).

Esse processo significou a manutenção e consolidação do poder daqueles que possuíam terras. Paralelamente, outras ações se dirigiram nessa mesma direção e ajudaram a criar um Estado não igualitário, clientelista e patrimonialista, com uma sociedade distinta da ideal do Estado moderno, conformada por grupos sociais com direitos desiguais (MARTINS, 2000, p. 27).

Temos, então, um panorama em que a propriedade da terra significa poder econômico e político, privilégios dentro de uma escala social diferenciada. Mas também temos um panorama em que público e privado se misturam, convivem de forma conflituosa, invadem-se mutuamente, porque, numa sociedade moldada na troca de favor e no clientelismo, não basta a distinção legal para separar ambas as esferas.

Nesse sentido, segundo Martins (1994, p. 21-22), no Brasil a distinção entre público e privado ficou restrita ao patrimônio público e ao patrimônio privado, à esfera da propriedade e não dos direitos das pessoas, sem ganhar, contudo, clareza nessa distinção. Essa falta de diferenciação clara do público e do privado significa, do ponto de vista da dominação política, a invasão da esfera do público pelo privado, no intuito de reproduzir, ampliar e/ou consolidar as relações de poder.

Desse modo, trazendo as análises anteriores para o espaço, no que se refere à produção do espaço urbano, também observamos uma difícil e tensa relação entre 
público e privado, especialmente quando analisadas as articulações entre o poder municipal e as elites locais, que tendem a se confundir e identificar em benefício dos detentores do poder. A seguir, tentaremos desenvolver essa linha de análise.

\section{I.I- O Poder Municipal, Espaço Público e Dominação}

A idéia do poder municipal como zelador dos interesses coletivos deve ser assumida como um ideal não cumprido ou, pelo menos, não cumprido totalmente. Em geral, a ação do poder municipal mostra uma mistura de interesses públicos e privados - que pode ir dos interesses próprios do prefeito até os interesses de grupos locais dominantes.

No processo de produção do espaço urbano, essa mistura de interesses, que pode ser lida como interesses em conflito, manifestase claramente. Como aponta Carlos (2001, p. 29), o espaço "se revela como instrumento político intencionalmente organizado", manipulado pelo Estado, nas mãos de uma classe dominante. Segundo Lefebvre (1976, p. 42), essa classe dominante dispõe de um duplo poder sobre o espaço: em primeiro lugar, através da propriedade privada do solo e, em segundo lugar, através da ação do Estado, representante dos seus interesses. "A ação do Estado - por intermédio do poder local - ao intervir no processo de produção da cidade reforça a hierarquia de lugares, criando novas centralidades e expulsando para a periferia os antigos habitantes, criando um espaço de dominação". (CARLOS, 2001, p. 15)

Esse espaço de dominação caracterizase por servir aos interesses do Estado de se apresentar como redutor das contradições, mesmo que somente no plano das aparências, porque a contradição é um aspecto marcante da sociedade capitalista e do espaço produzido por ela. Assim, Lefebvre (1992, p. 365-366) alerta-nos que o espaço do poder procura manter um aspecto de unidade e homogeneidade, mantendo unido o que está desunido, ligado o que está separado; o espaço mantido ao mesmo tempo afastado e próximo, apesar da heterogeneidade e das contradições que são representadas, como destacado na citação anterior, na hierarquia dos lugares e nas novas centralidades.

Nesse contexto, em termos gerais, podemos afirmar que a relação entre o poder municipal, o espaço urbano e a dominação política pode ser analisada em duas perspectivas: a primeira corresponde ao poder no espaço e a segunda ao poder do espaço.

O exercício do poder para o controle do espaço (poder no espaço) inclui a capacidade de definição/modificação das normativas legais de uso e ocupação do solo, as definições sobre política tributária, a implementação de infraestrutura, serviços e investimentos. Esse controle do espaço deve ser entendido como um controle da sociedade com vistas à dominação política.

Numa outra perspectiva, temos o poder do espaço, ou seja, o espaço produzido nas suas desigualdades e contradições possui a capacidade de facilitar ou dificultar o processo de dominação política. Assim, essa dominação pode ser mesmo questionada a partir do espaço e de suas características, no núcleo do processo da sua produção.

Essa situação nos remete ao conflito que se produz no espaço entre a dominação e a apropriação, ou seja, entre as tendências normativas da dominação e as tendências subversivas surgidas do uso e apropriação do espaço. Embora a dominação, ao que parece, tenda a ganhar essa batalha, como aponta Lefebvre (1992, p. 166), “não significa que a apropriação desapareça, isso não pode: prática e teoria continuam proclamando a sua importância e exigindo a sua restituição".

No caso específico do espaço público, é possível afirmar que a sua relação com o poder municipal é direta, já que este exerce o seu domínio - do ponto de vista legal -, constituindo-se, por excelência, no espaço da 
intervenção do poder público. Assim, o espaço público - especificidade - reflete as tensões do processo de produção do espaço urbano totalidade -, bem como reflete os múltiplos conflitos de interesses que, geralmente, se resumem como conflitos público-privado.

As diferentes administrações municipais procuram deixar as suas "marcas" no espaço público, assim como o utilizam como "moeda de troca" para fins eleitorais. Nesse sentido, as inaugurações e re-inaugurações de calçadas, parques e praças - além de outras obras, serviços ou equipamentos públicos - dificilmente são realizadas como se essas ações fossem consideradas próprias e cabíveis à administração municipal. Pelo contrário, as obras são apresentadas como corporificação da preocupação e da capacidade especial da autoridade. Assim, a obra fica personalizada e o voto fica comprometido, reproduzindo as relações de patrimonialismo e clientelismo que perpassam a sociedade brasileira desde tempos coloniais.

Ao estudar cidades pequenas e médias, essas relações parecem ficar mais claras, ou pelo menos são mais evidentes, pela forte concentração do poder e/ou pela maior visibilidade que ele pode ter. Essa concentração de poder propicia episódios que demonstram uma clara indefinição entre o que é público e o que é privado, mas também demonstra como o público parece se concentrar e, finalmente, personificar-se na figura do prefeito, remetendonos às práticas coronelistas.

\section{I.II- Elites Locais, Espaço Público e Dominação}

Para estudar a relação entre as elites locais, o espaço público e a dominação política, as análises devem centrar-se, a nosso ver, na tendência à produção de espaços voltados aos grupos de maior poder econômico e, conseqüentemente, de maior poder político, que passaremos a denominar de espaços próprios $^{2}$. Eles consolidam uma sociabilidade segmentada, já que os espaços próprios são também espaços exclusivos, que deixam à margem a diferença e os diferentes, para os quais restam os espaços abandonados ou deixados para trás pelas elites.

Como analisa Lefebvre (1992): “O espaço desta prática social se torna um espaço que tipifica - um espaço que classifica ao serviço de uma classe. A estratégia de classificação distribui os vários estratos sociais e classes [...] pelo território disponível, mantendo-os separados e proibindo todos os contatos estes são substituídos pelos sinais (ou imagens) de contato". (LEFEBVRE, 1992, p. 375, grifo do autor, tradução nossa)

O surgimento dos espaços próprios da elite está quase sempre associado ao questionamento da relação público-privado. Em primeiro lugar, porque os espaços da elite são fundamentalmente espaços privados ou de acesso restrito. Em segundo lugar, porque na produção desses espaços quase sempre está envolvido o poder público, seja por ação aplicação de recursos, implementação de obras, criação de leis - ou por omissão - deixando as coisas acontecerem à margem da legalidade.

Além desses aspectos, do ponto de vista simbólico, os grupos de maior poder econômico e político impõem ou tentam impor a sua cidade, ou seja, os seus espaços próprios como a cidade moderna, em oposição ao resto da cidade. Mas ao mesmo tempo em que criam seus espaços próprios com o objetivo da diferenciação, as elites são indistinguíveis umas das outras (LEFEBVRE, 1992, p. 380). Assim, erigem seus espaços como negação do atraso da sociedade brasileira, expresso de forma tão marcante na grande desigualdade das nossas cidades, querendo apagar o conteúdo desigual da sociedade por meio das formas que valorizam, ao mesmo tempo, a homogeneidade e a exclusão. Essa situação remete aos esforços modernizadores da elite nos inícios do período republicano brasileiro e demonstra como pouco temos avançado nesse sentido ${ }^{3}$.

Voltando aos espaços próprios, para as elites, ao que parece, a sua simples 
materialização implicaria na superação da desigualdade da sociedade brasileira e a equipararia aos padrões de consumo e moradia dos chamados países desenvolvidos. Nesse contexto, os espaços próprios apresentam a característica de ser ao mesmo tempo: globais ou homogêneos porque repetem as mesmas formas e tentam, assim, repetir os conteúdos, mesmo que só no plano da representação; são fragmentários porque fraturam o espaço urbano, não só do ponto de vista físico, mas também porque contribuem ao rompimento das relações; e, são hierárquicos porque se impõem (ou tentar se impor) como "a cidade" ou como a parte moderna da cidade.

\section{II- Produção de espaço público e acumulação de capital}

Neste ítem, desenvolveremos o segundo nível de análise, a partir do qual abordaremos a produção do espaço; assim, trataremos da relação entre o espaço urbano - especialmente na perspectiva do espaço público - e o processo de acumulação de capital.

Tomando Lefebvre como referencial, temos que a cidade é um produto no sentido amplo, assumindo a característica de obra, muito além de um simples produto material. Na cidade se produzem objetos, coisas, mas o fundamental é que nela se produzem relações sociais: produção e reprodução de seres humanos por seres humanos (LEFEBVRE, 1973, p. 64-65).

Para Lefebvre, o conceito de "produção" não se limita à fabricação de coisas. Entendida num sentido amplo - o filosófico - , a produção não deixa nada fora dela, compreende o mental, o intelectual, as idéias e representações. “Há produção das representações, das idéias, das verdades, assim como das ilusões e dos erros. Há produção da própria consciência" (LEFEBVRE, 1999a, p. 45).

No sentido amplo devemos considerar a produção de obras, de idéias, de espiritualidade, da própria sociedade. No sentido restrito há a produção de bens materiais ${ }^{4}$. Em função dessa conceituação: “[...] a cidade cobre bem a dupla acepção do termo 'produzir'. Obra ela mesma, é o lugar onde se produzem as obras diversas, inclusive aquilo que faz o sentido da produção: necessidades e prazeres. É também o lugar onde são produzidos e trocados os bens, onde são consumidos". (LEFEBVRE, 1999a, p. 51)

Ao relacionar espaço e produção, Lefebvre traz o dinamismo, o movimento da sociedade, a idéia de processo, de complexidade e de diversidade, dimensões deixadas de lado nas abordagens convencionais sobre o espaço. Mas o autor vai além, ao destacar que o espaço é também contraditório, produto do seu conteúdo social capitalista, que o comercializa, esmigalha e venda em pedaços. (LEFEBVRE, 1976, p. 42)

Essa realidade de espaço recortado,
vendido aos pedaços, remete ao desenvolvimento do mundo da mercadoria que alcança o espaço. O espaço social, produto do trabalho social, torna-se elemento gerador de mais-valia. Assim, “o espaço inteiro entra na produção como produto através da compra, da venda, da troca de parcelas do espaço" (LEFEBVRE, 1999b, p. 142).

Nesse sentido, o espaço urbano: “[...] surge como um produto de caráter singular que, às vezes, é simplesmente consumido (em formas como viagens, turismo ou atividades de lazer) como um artigo vasto e, às vezes, em áreas metropolitanas, produtivamente consumido (da mesma maneira que as máquinas, por exemplo), como um aparato produtivo de grande escala". (LEFEBVRE, 1992, p. 349, grifo do autor, tradução nossa)

Essa dinâmica de consumo do espaço simplesmente consumido e produtivamente consumido - determina que a produção, comercialização e consumo do espaço urbano se convertam em aspectos fundamentais da própria reprodução e acumulação do capital. A cidade vendida aos pedaços - criada, destruída e recriada, vendida novamente, valorizada ou 
desvalorizada, renovada, enobrecida ${ }^{5}$, abandonada, apresentada na embalagem de um novo produto imobiliário a ser comprado ou consumido - torna-se parte integrante da reprodução capitalista, não só porque nela são produzidos e trocados bens materiais e imateriais, ou porque nela, num sentido amplo, a sociedade como um todo é reproduzida, mas também, num sentido que poderíamos considerar restrito, porque a cidade ela mesma passa a ser um produto consumido, comprado e vendido, assumindo uma função fundamental na circulação e acumulação de capital.

Num sentido mais geral, Harvey (2003) afirma que: "O capitalismo não pode se manter sem as suas 'soluções espaciais'. Uma e outra vez, tem recorrido à reorganização geográfica (à expansão e à intensificação) como solução parcial das suas crises e pontos mortos. O capitalismo, portanto, constrói e reconstrói uma geografia à sua própria imagem". (HARVEY, 2003, p. 72 , tradução nossa) ${ }^{6}$

Seguindo esse raciocínio, a cidade também é construída e reconstruída à imagem do capitalismo, no sentido de auxiliar na superação das suas crises e constituir-se como parte das "soluções espaciais"7 adotadas como ajustes nos sistemas produtivos e nas formas de circulação e consumo.

Nesse contexto, Carlos (2001) ressalta: "Parece não haver dúvida de que a cidade se reproduz, continuamente, como condição geral do processo de valorização gerado no capitalismo no sentido de viabilizar os processos de produção, distribuição, circulação, troca e consumo e, com isso, permitir que o ciclo do capital se desenvolva e possibilite a continuidade da produção, logo, sua reprodução". (CARLOS, 2001, p. 15)

Da análise de Carlos (2001), desenvolvida a partir da realidade da metrópole paulistana, trazemos a idéia da "raridade do espaço", ou seja, a estratégia por transformar, recriar, mudar formas e conteúdos de parcelas da cidade, para integrá-las no circuito da compra e venda, com vistas ao desenvolvimento ou consolidação de novos padrões de consumo de espaço para residências, lazer ou trabalho. Assim, o espaço é artificialmente tornado raro para que alcance um "valor" mais elevado (LEFEBVRE, 1976, p. 107). A raridade produzida no espaço é contraditória, já que "raro" - como poderia se pensar num primeiro momento - não quer dizer "único" ou "incomum", pelo contrário, a raridade compreende a repetição de padrões arquitetônicos, urbanísticos e paisagísticos, possíveis de se encontrar em qualquer espaço metropolitano mundial que passe por dinâmicas semelhantes.

Por outro lado, essa raridade do espaço surge, em parte, pela escassez identificada por Carlos (2001, p. 22) para o crescimento em extensão na metrópole de São Paulo, situação oposta à encontrada em cidades médias, nas quais, em geral, dispõe-se de grandes áreas para a expansão territorial urbana. Nesses casos, a raridade está associada ao surgimento de um espaço novo, identificado como novos produtos imobiliários que se apresentam em oposição aos bairros já existentes que passam a ser considerados como velhos. Esse processo responde à luta contra a obsolescência demasiado lenta dos produtos imobiliários e acelera desse modo o ciclo do capital.

$\mathrm{Na}$ perspectiva das análises de cidades médias, fazem-se necessários alguns ajustes quando pensada a dinâmica da acumulação capitalista, não porque ela não exista - ela está presente em cada parcela do espaço -, mas porque ela se manifesta em magnitudes ou intensidades diferenciadas se comparada com o mesmo processo num espaço metropolitano.

Nesse contexto, é preciso apontar que, na metrópole, pensando especialmente no caso de São Paulo, os processos relacionados com a reprodução e acumulação capitalistas são muito mais intensos, engajados em dinâmicas globais de circulação de capitais, capazes de modificar radicalmente formas e conteúdos de importantes parcelas do espaço urbano, como no caso da Operação Urbana Faria Lima, analisado por Carlos (2001). 
Numa cidade média os impactos de uma dinâmica de acumulação manifestam-se de forma diferenciada, ou seja, existem processos de acumulação e reprodução de capital, mas dificilmente da mesma magnitude que num espaço metropolitano. Mas, essa intensidade diferenciada não significa que as tensões entre os espaços públicos e privados - ou em termos mais gerais entre as esferas do público e do privado -, na perspectiva da acumulação capitalista, tenham que ser analisadas como sendo menores ou menos agudas. Pelo contrário, o surgimento de um novo produto imobiliário - como um shopping center, por exemplo -, que em termos de capitais movimentados, volumes de vendas ou superfície construída, em comparação com os de um espaço metropolitano, pode ser muito menor, na perspectiva do impacto sobre a relação público-privado, adquire uma dimensão muito mais visível, até agressiva e com repercussões que, potencialmente, podem ser sentidas de maneira mais intensa em outras parcelas do espaço urbano, quando se analisam espaços urbanos não-metropolitanos.

\section{II.I- Novos Produtos Imobiliários: Novas Formas para Consumo, Lazer e Moradia}

O surgimento de novos produtos imobiliários - como shopping centers e loteamentos fechados repercute direta e fortemente na relação público? privado. O foco das análises deve ser sempre essa relação e não o espaço público isoladamente, já que defendemos que é preciso analisar o público na sua relação com o privado, ainda mais neste caso, quando as atividades, para as quais os novos produtos imobiliários se orientam, envolvem sempre, ou quase sempre, relações entre essas duas esferas. Nesse sentido, pense-se no ato de morar e sua relação entre casa e rua; no ato de consumir e a interface entre loja e rua; ou no lazer, que pode ocorrer em espaços públicos, privados ou em ambos.

Os shopping centers e os loteamentos fechados representam produtos que expressam novas formas e práticas para antigas ações consumo, lazer e moradia - contribuindo na sua materialização para o processo de acumulação de capital. Em termos gerais, esses produtos imobiliários formam parte de uma categoria mais ampla, que Caldeira (2000) chama de "enclaves fortificados".

Esses "novos produtos" alimentam, reforçam e respondem ao desejo de um segmento da população - o de maior poder aquisitivo - de se diferenciar, dispondo na cidade de seus espaços próprios, como analisado anteriormente. A dinâmica de produção dos enclaves fortificados pode ser lida, considerando as características do espaço identificadas por Lefebvre (1992, p. 282), como parte da tendência do processo de acumulação capitalista para criar um espaço global e homogêneo, repetindo os mesmos processos e produtos imobiliários, já que esses empreendimentos podem ser encontrados nas diversas cidades, embora sejam menos freqüentes em cidades pequenas. Também, a mesma dinâmica fragmenta os espaços, pois os enclaves têm poucas ou nulas relações com as suas adjacências, e hierarquiza os lugares, uma vez que a reprodução do capital separa e tende a ressaltar as especificidades dos lugares para facilitar a sua comercialização, potencializando os espaços que dispõem dessas novas formas de moradia, consumo, lazer e produção, tanto no interior de uma mesma cidade, como nas relações entre cidades, gerando processos de circulação - comunicações e transporte -, cujos exemplos mais claros são os deslocamentos diários daqueles que trabalham nesses espaços e os fluxos daqueles que se deslocam para consumir neles. Por outro lado, esse processo também modifica as práticas de consumo comandadas por valores subjetivos e ideológicos que expressam o desejo de dispor desses novos espaços, que passam a ser conceituados como indicadores da modernização.

No mesmo sentido, é necessário destacar novamente que, apesar de se tratar de uma dinâmica global - lida a partir da reprodução e acumulação de capital -, ela não se manifesta da mesma maneira nem com a mesma intensidade em todos os lugares. Assim, é possível encontrar todos os tipos de enclaves fortificados na metrópole, mais ligados com os processos globais de circulação de capital e com um mercado potencial muito maior. No entanto, na medida em que nos afastamos, física e 
demograficamente das grandes aglomerações urbanas, veremos que, em cidades grandes e médias, os mesmos produtos imobiliários não se apresentam na mesma intensidade e sob a mesma diversidade de formas.

Analisando o processo de acumulação de capital de outra perspectiva, em função da forte desigualdade socioeconômica da nossa sociedade e da retração dos níveis de crescimento e de poder aquisitivo, uma grande parcela da população fica fora do mercado porque não tem capacidade de consumir, diminuindo a demanda solvente para os produtos imobiliários. Assim, as estratégias de reprodução de capital devem criar novos produtos para vender novas formas, deixando obsoletas as antigas, apresentando o novo e o moderno como desejo e aspiração para o segmento que possui a capacidade financeira para os consumir. Como aponta Lefebvre (1991, p. 91): "Para que a usura 'moral' e a obsolescência das coisas trabalhem rapidamente, é preciso também que as necessidades envelheçam, que jovens necessidades as substituam. É a estratégia do desejo!". Dessa maneira, para os já proprietários são apresentadas novas formas de moradia, consumo e lazer, permitindo que entrem novamente no circuito de consumo, de forma que a cidade seja novamente vendida (SOBARZO e SPOSITO, 2003, p. 42).

Esse processo que contrapõe o novo ao antigo tem fortes conseqüências nas cidades médias, podendo ser sentidas de maneira ainda mais forte que nos espaços metropolitanos. Com efeito, o impacto de uma nova forma de morar ou de consumir, em função do tamanho do mercado de uma cidade média, pode significar um processo muito mais acentuado de obsolescência das antigas formas de morar ou consumir. Sposito (2004, p. 379) destaca essa tendência como parte de um ideário urbano que, no plano simbólico, associa o moderno ao novo e por sua vez eles à vida metropolitana. Nesse sentido, o impacto da implementação de um shopping center para o comércio da área central de uma cidade média pode consolidar a retirada dele dos segmentos de maior poder aquisitivo e reforçar o seu processo de "popularização". Muitas cidades não têm, ou não têm ainda, demanda solvável para a manutenção dessas duas áreas comerciais. Esse fato, juntamente com o desejo da elite de espaços próprios e exclusivos, impacta fortemente o conjunto do espaço urbano. No espaço metropolitano, no qual se dispõe de uma demanda solvável muito maior, é possível a coexistência não somente de vários shopping centers, mas também de outras áreas comerciais abertas, inclusive de alto padrão. Assim, o shopping não adquire tão fortemente valorização como decorrente de ser a única, ou quase a única alternativa para o consumo de certos extratos sociais, como ocorre nas cidades médias.

Uma análise similar comporta o caso dos loteamentos fechados, que tendem a se consolidar, especialmente no plano simbólico, como a forma moderna de morar, própria dos grupos de maior poder aquisitivo. Ainda mais, em cidades médias, em comparação com espaços metropolitanos, os menores preços da terra urbana - influenciados pela maior disponibilidade de áreas loteáveis - e os custos de vida e de construção comparativamente menores facilitam o acesso a esse tipo de produto imobiliário até para grupos de poder aquisitivo médio. Para Sposito (2004, p. 374), esses fatos provocam as classes médias a se incluírem na demanda solvável para imóveis de alto padrão e nos segmentos com possibilidades de substituir os imóveis que possuem pelos novos produtos oferecidos.

Essa dinâmica não só se explica pelos custos menores de acender às novas formas de moradia, mas também porque uma fração dos segmentos médios, por meio do consumo, tenta imitar as elites e, por sua vez, é imitada por segmentos de menor poder aquisitivo (LEFEBVRE, 1976, p. 111), numa espécie de "efeito cascata", que explica, em parte, o grande prestígio simbólico que essas novas formas de morar possuem em amplos setores da sociedade. Com isso, antigos bairros abertos ocupados pelos segmentos altos e médios são 
afetados pelo surgimento de uma nova forma de morar.

No contexto da valorização do capital, é claro que na metrópole os produtos imobiliários analisados têm um impacto muito maior, já que envolvem quantidades e fluxos de investimentos também maiores. Na perspectiva de uma cidade média, as cifras investidas e movimentadas podem ser menores, mas os impactos no conjunto da cidade podem ser sentidos mais evidentemente, especialmente, na relação público-privado.

\section{III- Produção e apropriação do espaço público}

Nos dois pontos anteriores, as análises centraram-se nas relações do espaço público com as esferas da política e da reprodução econômica, níveis de análise principalmente ligados ao campo da dominação. No primeiro caso, trata-se da dominação política analisada por meio das ações do poder municipal e das elites locais na produção do espaço urbano. No segundo caso, da dominação econômica, as reflexões giraram em torno dos processos hegemônicos de acumulação e reprodução do capital.

Neste ítem, em que abordaremos o nível da realização da vida humana, o foco deslocase da dominação para a apropriação do espaço, ou seja, para as relações socioespaciais produzidas pelo uso, nas práticas cotidianas que conformam o plano do vivido e que constróem a identidade e o sentimento de pertencimento das pessoas. Podemos pensar a leitura da produção do espaço público em termos da dominação, como relações de verticalidade ou processos "vindos de cima" que alteram o caráter do público na cidade. No caso da produção e apropriação desses espaços pelo uso, as relações podem ser lidas na horizontalidade, como uma metáfora de trajetórias no espaço de pessoas, que no seu dia-a-dia, constróem (e são construídas), modificam (e são modificadas) e dão (encontram) sentidos ao (no) espaço público.
As palavras de Milton Santos (1997), embora pensadas numa outra circunstância de análise, resumem bem essa reflexão:

As verticalidades são vetores de uma racionalidade superior e do discurso pragmático dos setores hegemônicos, criando um cotidiano obediente e disciplinado. As horizontalidades são tanto o lugar da finalidade imposta de fora, de longe e de cima, quanto o da contrafinalidade, localmente gerada. Elas são o teatro de um cotidiano conforme, mas não obrigatoriamente conformista, e, simultaneamente, o lugar da cegueira e da descoberta, da complacência e da revolta. (SANTOS, 1997, p. 227)

Nesse contexto, as análises da apropriação procuram explorar a relação com o cotidiano e a construção de identidade e as possibilidades de transformação e mudança a partir da apropriação dos espaços públicos.

\section{III.I- Apropriação, Cotidiano e Espaço Público}

Aqui trataremos da apropriação no sentido amplo: apropriação dos espaços públicos, por meio do uso, para a realização da vida das pessoas no seu cotidiano. Nesse sentido, Lefebvre (1975) define a apropriação como a finalidade da vida social e a contra-põe à dominação ${ }^{8}$.

Mas essa oposição entre dominação e apropriação não pode ser entendida como uma dicotomia entre termos excludentes. Para Lefebvre (1992, p. 165, grifo do autor, tradução nossa), “o conceito [de dominação] só atinge seu significado pleno quando é contrastado com o conceito oposto e inseparável de apropriação". Nesse sentido, embora a dominação, no processo histórico do capitalismo, pareça ganhar ou se impor à apropriação, esta última não desaparece, continua sendo presente e importante. É, justamente, na esfera da vida cotidiana que ambos os conceitos e também ambos os espaços (espaço dominado e espaço apropriado) se manifestam e podem ser lidos 
claramente na sua inter-relação (LEFEBVRE, 1992, p. 166 e 366).

Como analisa Carlos (1996, p. 144-145), “o cotidiano não se restringe às atividades de rotina, nem tampouco a atos isolados, isto porque no cotidiano se realizam as coações e se gestam as possibilidades". Nesse sentido, as coações estão ligadas à dominação, enquanto as possibilidades se relacionam com a apropriação e a potencial subversão que, por meio do uso, são possíveis de se contraporem a essa tentativa de dominação. O cotidiano resume e funde a tendência global da difusão do consumo de massa e a irrupção de um modo de vida associado a valores do consumo e das necessidades criadas e, por outro lado, também inclui a possibilidade da superação e da criação do novo, das insurgências (CARLOS, 1996, p. 145) ou da subversão como apontamos anteriormente.

Segundo Lefebvre (1991), a vida cotidiana expressa um equilíbrio momentâneo e provisório entre produção e consumo, estruturas e superestruturas, conhecimento e ideologia, relações que permitem considerá-la ao mesmo tempo como resíduo e como produto do conjunto social. No plano da dominação, o cotidiano se reduz ao âmbito das mercadorias, do consumo, da prevalência do valor de troca sobre o valor de uso. Mas como apontamos anteriormente, junto à dominação existe a apropriação no cotidiano e com ela as possibilidades de transformação, do novo.

Nesse contexto, são fundamentais os aportes de De Certeau, que destaca a capacidade dos usuários ${ }^{9}$ de superar a condição de meros consumidores passivos e dominados. Para esse autor, as "maneiras de fazer" cotidianas são caracterizadas pela criatividade e "constituem as mil práticas pelas quais usuários se reapropriam do espaço organizado pelas técnicas de produção sócio-cultural", chegando a compor, em última instância, a "rede de uma antidisciplina" (DE CERTEAU, 2003, p. 41-42).

Assim, os usuários e as suas maneiras de se apropriar do espaço constituem uma superação da racionalidade planejada e dominante que tenta se impor na cidade. O espaço da apropriação é o espaço do usuário; o espaço do vivido. A vida cotidiana remete à relação entre espaços de representação (vividos, concretos, subjetivos, apropriados) e as representações do espaço (abstratas, objetivas, dominadoras).

Voltando às palavras de De Certeau (2003, p. 172), a relação entre as "maneiras de fazer" e o surgimento de "uma outra espacialidade", ligada à "experiência antropológica, poética ou mítica do espaço", que podemos resumir como a apropriação do espaço no cotidiano, conduz as nossas reflexões ao conceito de lugar. Como o autor especifica: "o espaço é um lugar praticado. Assim, a rua geometricamente definida por um urbanismo é transformada em espaço pelos pedestres" (DE CERTEAU, 2003, p. 202, grifo do autor).

A introdução do conceito de lugar nas nossas reflexões possibilita avançar no sentido de incorporar a capacidade que a vida cotidiana e a apropriação do espaço possuem na construção da identidade das pessoas, do subjetivo ligado ao vivido, às experiências do uso, que vão além da simples materialidade do espaço já que envolvem aspectos do imaginário e do simbólico, incluindo a potencialidade de mudança e transformação.

O conceito de lugar é claramente definido por Carlos (1996, p. 20) quando, partindo da tríade habitante-identidade-lugar, o define como: “a porção do espaço apropriável para a vida - apropriada através do corpo - dos sentidos - dos passos de seus moradores, é o bairro, é a praça, é a rua [...]". Os lugares relacionam-se ao cotidiano das pessoas, são locais apropriados pelo uso, espaços do vivido, carregados de significado, que criam a identidade. Ainda, a autora nos alerta para não conceber o lugar de forma autônoma, como se tivesse vida própria, mas na sua articulação com a totalidade espacial, considerando as suas relações com o caráter social e histórico da 
produção do espaço geográfico global (CARLOS, 1996, p. 21-22 e 33).

No momento atual, essa relação do lugar com o global implica num conflito entre novos modelos culturais e de comportamento, ligados ao consumo e ao mundo da mercadoria, e às especificidades das relações da vida no lugar. A irrupção de uma rotina organizada da vida cotidiana transforma radicalmente a sociabilidade, ao transformar os usos e as formas de relacionamento dos e nos lugares, significando a redefinição da prática socioespacial. Nesse processo, o Estado também cumpre um papel importante porque pretende organizar a vida cotidiana, normatizando os usos (CARLOS, 2004, p. 21-22, 26-27).

Antes de continuar com as análises, consideramos necessário avançar na relação entre vida cotidiana, lugar e espaços públicos. Um autor que auxilia nessa tarefa é Mayol (2002) por meio das análises que realiza sobre o bairro, mas que consideramos serem possíveis de projetar para outros lugares (centro da cidade, praça, rua). O autor citado concebe a apropriação como "uma privatização progressiva do espaço público", determinada pelo seu uso habitual (MAYOL, 2002, p. 42).

A apropriação, nessa perspectiva, dá significado ao espaço público, interligando as esferas do privado e do público. A apropriação constitui, assim, um prolongamento do privado no público, efetuado mediante o uso, tratando-se, desse modo, de uma "privatização corporal" porque feita pelo corpo do habitante que sai do espaço privado da casa (dentro) e vai "conquistando" para seu uso, para sua vida e, em último termo, para a sua reprodução uma parcela do espaço público (fora) definida pelas suas trajetórias. "E é na tensão entre esses dois termos, um dentro e um fora, que vai aos poucos se tornando um prolongamento de um dentro, que se efetua a apropriação do espaço". (MAYOL, 2002, p. 42, grifo do autor)

A consideração da apropriação como uma privatização do espaço público na escala do corpo dos usuários inter-relaciona as esferas do público e do privado, mas também significa uma relação interescalar porque, embora falemos que a apropriação é realizada na escala do corpo, na verdade, o usuário, a partir do seu corpo, "conquista" uma outra escala representada no espaço público do bairro, do centro da cidade ou num daqueles "pedaços" de cidade definidos pelas suas trajetórias ${ }^{10}$. Utilizando a tipologia "incompleta e aberta" apresentada por Smith (2000) das diferentes escalas geográficas, podemos conceber a apropriação do espaço público como uma instância de "salto escalar"11 que permite sair da escala do corpo e da casa (âmbitos privados) para as escalas da comunidade ou do bairro e do espaço urbano ou de fragmentos dele.

Nesse sentido, devemos superar a separação dicotômica entre público e privado para compreender a apropriação e avançar no sentido de uma concepção em que a complementariedade esteja presente, ainda que plena de contradições. Não se trata de dois âmbitos separados, mas unidos nas suas diferenças ${ }^{12}$.

Assim, os espaços públicos e a relação do público e do privado devem ser analisados e considerados como produtores e como produtos da apropriação, criando relações de identidade e de reconhecimento para os seus usuários. Na condição de lugares - o calçadão, a praça central, a praça do bairro, a rua comercial, a rua de residência, o parque - esses espaços públicos permitem analisar a interação público-privado na apropriação pelo uso definido nas práticas cotidianas.

\section{III.II- Apropriação do Espaço Público e Possibilidades de Subversão}

Como afirmamos anteriormente, o espaço urbano exprime a relação entre dominação e apropriação. Constitui-se como um campo moldado pelas ações do Estado e dos extratos sociais que representa, do ponto de vista da dominação, mas que também permite a apropriação definida pelo uso no processo da reprodução da sociedade, expresso na vida cotidiana e capaz de criar novas possibilidades.

Lefebvre (apud Brenner, 2000, p. 370) desenvolveu na sua obra De l'État (1976-1978) 
as principais formas da intervenção do Estado no capitalismo: a) mobiliza o espaço como uma força produtiva mediante variadas formas de investimentos em infraestrutura, planejamento espacial, políticas industriais e financiamentos dirigidos para diferentes locais e escalas geográficas; b) opera como mediador institucional do desenvolvimento geográfico desigual; c) organiza diversas estratégias para hierarquizar as relações sociais em diferentes escalas geográficas, atuando simultaneamente para manter a coesão social e impor uma diferenciação funcional no espaço.

São essas intervenções que comandam o processo da produção do espaço da dominação, como um espaço abstrato, instrumental à reprodução capitalista. No entanto, no centro desse processo está a vida e a sua dinâmica de reprodução que modificam a abstração trazendo o processo ao plano do vivido, do concreto e subjetivo.

Como ressalta Lefebvre (1992, p. 349), o espaço cumpre um papel entre as forças de produção e apresenta-se politicamente instrumental, facilitando o controle da sociedade, mas também contém potencialidades e, na resistência, inaugura o projeto de um espaço diferente. É no plano do vivido, da apropriação cotidiana que o espaço se abre às possibilidades.

Nesse contexto, Carlos (1996, p. 145 e 148) - baseada em Lefebvre - analisa o cotidiano como o lugar da superação, o lugar do novo, onde as coações, mas também as insurreições estão presentes. Assim, o cotidiano deve ser entendido como: “[...] um campo e uma renovação simultânea, uma etapa e um trampolim, um momento composto de momentos (necessidades, trabalho, diversão - produtos e obras - passividade e criatividade - meios e finalidade etc.), interação dialética da qual seria impossível não partir para realizar o possível (a totalidade dos possíveis)". (LEFEBVRE, 1991, p. 20)

A capacidade de construção desses possíveis a partir da esfera da vida cotidiana é real. Segundo Lefebvre (1992, p. 366), a "totalidade" também depende do "nível micro" ou da esfera da vida cotidiana, embora esse nível não consiga fornecer "o teatro do conflito ou a esfera na qual as forças em conflito são desdobradas". Contudo, a vida cotidiana possibilita a ocupação do espaço e a materialização de uma prática espacial, e como o autor frisa: “Uma prática espacial destrói a prática social; a prática social se destrói por meio da prática espacial".

Nesse contexto, retomamos os aportes de De Certeau (1994, p. 41 e 47) no sentido de considerar as ações cotidianas como táticas, ou seja, um jogo entre os acontecimentos que permite aproveitar a ocasião e compor uma antidisciplina. No cotidiano é possível cultivar as resistências, como destaca Carlos (2001): "no cotidiano o cidadão se encontra diante de coações e vigilância; mas na repetição também pode surgir a essência do imaginário, na medida em que há brechas no cotidiano que abrem espaço para o criativo e para o virtual [...]". (CARLOS, 2001, p. 303-304)

Mas quem está chamado à subversão e à antidisciplina? Consideramos que são aqueles que, nas atuais condições da reprodução capitalista, se encontram nas situações mais desfavoráveis: os grupos de menor poder aquisitivo. Como aponta Milton Santos (1997):

Por serem "diferentes", os pobres abrem um debate novo, inédito, às vezes silencioso, às vezes ruidoso, com as populações e as coisas já presentes. [...]

Trata-se, para eles, da busca do futuro sonhado como carência a satisfazer - carência de todos os tipos de consumo, consumo material e imaterial, também carência do consumo político, carência de participação e de cidadania. Esse futuro é imaginado ou entrevisto na abundancia do outro e entrevisto, como contrapartida, nas possibilidades apresentadas pelo Mundo e percebidas no lugar. (SANTOS, 1997, p. 261)

Nessa perspectiva, das possibilidades percebidas no lugar, a apropriação característica dos 
grupos de menor poder aquisitivo, que denominamos de "privatização corporal" do espaço público, deve ser valorizada como uma instância chave da reprodução social e das possibilidades de transformações e insurgências. O pobre convive com o lugar, apropria-se do espaço público, interage com outros - mesmo que numa prática de sociabilidade segmentada - e ao criar laços de reconhecimento e identidade pode adquirir a consciência que o leve à transformação. No lado oposto, a "apropriação limitada" das classes altas e médias alimenta o seu conformismo e "cria uma mecânica rotineira, um sistema de gestos sem surpresa" nas suas áreas de modernidade que ficam reduzidas a espaços "fechados, racionalizados e racionalizadores" (SANTOS, 1997, p. 261).

A relação entre apropriação, cotidiano, espaço público e subversão pode ser compreendida por meio da produção da escala geográfica. Como apontamos anteriormente, a apropriação do espaço público pode ser entendida como uma instância de "salto escalar" que permite sair da esfera do privado - corpo e casa - para escalas maiores como o bairro e a cidade. A escala geográfica deve ser entendida como uma produção social no sentido amplo, embora, num primeiro momento as análises tenham privilegiado o papel do capital na sua construção, identificando as escalas espaciais do capital (SMITH, 1988). Reflexões posteriores, especialmente as de Smith (1992, 2000), avançaram na perspectiva de consolidar o entendimento da produção da escala geográfica como uma construção resultante das atividades e relações econômicas, políticas e sociais, como expressão da ação social coletiva, portanto relacionada às disputas e lutas sociais.

Smith (2000) reflete sobre a importância do acesso pelo corpo a espaços mais amplos ou o acesso corporal como meio de saltar escalas. É nesse sentido que pensamos a apropriação do espaço público como possibilitadora de ações de subversão, porque os usuários - os pobres urbanos - ao se apropriarem dos lugares podem conquistar diferentes âmbitos de luta, saindo do lugar para tentar se apropriar do espaço em escalas mais amplas. Como aponta Guimarães (2004, p. 17), "quanto mais um ator político é capaz de atuar em diferentes escalas, maior o seu poder de decisão sobre a produção do espaço".

Na mesma perspectiva, Brenner (2000, p. 375-376) reconhece que a capacidade de saltar escalas aumenta a influência dos atores no espaço social e destaca que a transformação da realidade urbana deve ser decidida politicamente nas lutas cotidianas, com o intuito de posteriormente influenciar nas escalas nacional, supranacional e global por meio de contra-políticas orientadas à construção de uma sociedade mais justa.

No contexto da nossa reflexão interessa-nos destacar as potencialidades de transformação na escala do espaço urbano por meio da apropriação cotidiana dos espaços públicos. Reconhecemos que subversões nessa escala podem ter conseqüências em escalas superiores, mas essa análise escapa aos nossos propósitos.

Dentro desse alcance, concordamos com Smith (2000) quando afirma que: "[...] uma política da escala pode se tornar também uma arma de expansão e de inclusão, um meio de ampliar as identidades. As escalas oferecem marcos na recuperação do espaço da aniquilação e uma linguagem mediante a qual a rediferenciação do espaço pode ser desbravada sobre bases sociais discutidas e ajustadas, em vez de seguir a lógica econômica do capital e os interesses políticos de sua classe". (SMITH, 2000, p. 157)

Na escala urbana podemos pensar a apropriação como uma conquista do lugar para a conquista do espaço ${ }^{13}$ (o bairro e a cidade e, potencialmente, escalas superiores em outras instâncias). Seria um exercício de táticas cotidianas - nas palavras de De Certeau -, potenciais momentos de insurgências, subversão, antidisciplina, contra-políticas e transformação.

Nesse contexto, é fundamental pensar a apropriação do bairro como uma experiência coletiva criadora do pertencimento - nosso bairro, nossa rua, nossa praça, nosso lugar. Como já analisamos, essa primeira apropriação constitui um "salto escalar" que permite sair do indivíduo e da família (corpo e casa) para a comunidade. Num segundo momento, as trajetórias pela cidade que a apropriam cotidianamente - e que constituem um "salto 
escalar" da comunidade para a cidade - permitem fazer uma leitura do outro, daquilo que é diferente. Nesse sentido, a apropriação permite o reconhecimento, que não se esgota no fato de se reconhecer diferente, mas a partir disso ser capaz de perceber a injustiça dessa diferença, produto dos conflitos expressos no espaço urbano, já que, como aponta Lefebvre (1992, p. 365): "para os conflitos serem expressos, devem primeiro ser percebidos".

Acreditamos que a conjunção de pertencimento e reconhecimento pode levar à mobilização social como forma de superação dos conflitos e de subversão e transformação da realidade. $O$ embate entre o espaço abstrato da dominação - representações do espaço - e o espaço concreto e subjetivo da apropriação espaços de representação - evidencia os conflitos e as contradições do espaço urbano.

As reflexões apresentadas levam-nos a pensar a apropriação do espaço público, no contexto da teoria da produção da escala geográfica, como um caminho de articulação e ação política para a expressão dos conflitos e sua potencial superação. Utilizando os termos cunhados por Lefebvre, podemos pensar que a apropriação do espaço público - do bairro, da cidade - possibilita a leitura das isotopias e das heterotopias e, nesse contexto, pode articular o movimento para as utopias - a transformação, a subversão.

Nas palavras de Milton Santos (1997): “Então, o feitiço se volta contra o feiticeiro. O consumo imaginado, mas não atendido - essa 'carência fundamental' no dizer de Sartre -, produz um desconforto criador. O choque entre cultura objetiva e cultura subjetiva torna-se instrumento da produção de uma nova consciência". (SANTOS, 1997, p. 261)

Essa nova consciência pode significar a mobilização social que, acreditamos, deve ser concebida e conduzida por movimentos sociais verdadeiramente populares, sem a participação dos partidos políticos nem de organizações sem um real compromisso social. Um movimento popular que abandone e supere as concepções baseadas no assistencialismo e no clientelismo eleitoral, que lute por direitos verdadeiros e que crie consciência cidadã, especialmente no sentido de conceber as ações e as obras do poder público não como respostas da boa vontade ou da capacidade e preocupação especial das autoridades e sim como um dever das administrações e um direito das pessoas.

Temos clareza de que esse processo não se resolve e materializa totalmente na esfera da apropriação do espaço. Evidentemente, fazemse necessárias outras frentes de ação para a criação da consciência cidadã nos planos da educação, do trabalho, da saúde, da habitação, da auto-estima, mas acreditamos ser extremamente importante reconhecer o papel que o espaço pode desempenhar no processo de mudança.

Ao considerar a apropriação cotidiana dos espaços públicos como um primeiro estágio da articulação escalar com vistas à geração de processos de transformação e mudança social na escala da cidade, acreditamos ter contribuído para o avanço na perspectiva do apelo de Harvey (2003, p. 67) sobre a "necessidade de conectar o micro-espaço do corpo com o macro-espaço do que agora é chamado de 'globalização'". Trata-se de uma contribuição modesta, que conecta o corpo, a casa, o bairro e a cidade a partir da apropriação, mas que deixa aberta a possibilidade de futuras reflexões e posteriores articulações.

Em resumo, apropriação do espaço público, construção do lugar, identidade e reconhecimento, considerados como momentos de criação e movimento para vislumbrar uma alternativa. Deixar de lado a espera e criar a esperança, avançando na procura de novos caminhos para a mudança.

Essa busca de caminhos é, também, visão iluminada do futuro e não apenas prisão em um presente subalternizado pela lógica instrumental ou aprisionado num cotidiano vivido como preconceito. É a vitória da individualidade fortalecida, que ultrapassa a barreira das práxis repetitivas e se instala em uma práxis libertadora, a práxis inventiva de que fala H. Lefebvre. (SANTOS, 1997, p. 262, grifo do autor) 
1 Como analisado por Sennett (1978).

2 A expressão "espaços próprios" envolve a mesma idéia expressada por Carlos (1996) ao utilizar o termo "guetos urbanos" e por Seabra (2004) quando usa o termo "territórios exclusivos".

3 Cf. SEVCENKO, 2002, p. 27.

4 "No sentido amplo, há produção de obras, de idéias, de 'espiritualidade' aparente, em resumo, de tudo que faz uma sociedade e uma civilização. No sentido estrito, há a produção de bens, de alimentação, de vestuário, de habitação, de coisas. Este último sentido apóia o primeiro e designa a sua 'base' material". (LEFEBVRE, 1999a, p. 46, grifo do autor)

“A produção não se reduz à fabricação de produtos. O termo designa, de uma parte, a criação de obras (incluindo o tempo e o espaço sociais), em resumo, a produção 'espiritual', e, de outra parte, a produção material, a fabricação de coisas. Ele designa também a produção do 'ser humano' por si mesmo, no decorrer do seu desenvolvimento histórico. Isso implica a produção de relações sociais. Enfim, tomado em toda a sua amplitude, o termo envolve a reprodução. Não há apenas reprodução biológica (e conseqüente aumento demográfico), mas também reprodução material dos utensílios necessários à produção, instrumentos técnicos e, ainda, reprodução das relações sociais". (LEFEBVRE, 1991, p. 37, grifo do autor)

5 Estamos usando termo "enobrecimento" no sentido do processo de gentrification, que alguns autores têm traduzido como "gentrificação".

${ }^{6}$ David Harvey vem desenvolvendo esta idéia desde o começo da década de 1980. Na obra citada o autor remete a seu livro The limits to capital, publicado em 1982.

7 Quando nos referimos à cidade como elemento fundamental na acumulação de capital ou da reprodução do capitalismo, não deixamos de considerar que, nesse processo, existem agentes, empresas, corporações, organizações e/ou instituições que lucram e comandam essa reprodução. A nossa análise não tem como intenção "personificar" ou "corporificar" o capitalismo ou a cidade, no sentido de reconhecê-lo como agente das mudanças.

8 "O conceito de apropriação é um dos mais importantes que nos tem podido legar séculos de reflexão filosófica. A ação dos grupos humanos sobre o meio material e natural tem duas modalidades, dois atributos: a dominação e a apropriação. Deveriam ir juntas, mas freqüentemente se separam. A dominação sobre a Natureza material, resultado de operações técnicas, arrasa essa Natureza permitindo às sociedades substituí-la pelos seus produtos. A apropriação não arrasa, mas transforma a Natureza - o corpo e a vida biológica, o tempo e o espaço disponibilizados em bens humanos. A apropriação é a meta, a finalidade da vida social. Sem a apropriação, a dominação técnica sobre a Natureza tende ao absurdo, na medida em que aumenta. Sem a apropriação, pode existir crescimento econômico e técnico, mas o desenvolvimento social propriamente tal se mantém nulo". (LEFEBVRE, 1975, p. 164-165, tradução nossa)

9 Estamos usando o termo "usuário" no sentido dado por Lefebvre por meio da palavra "usager". Segundo Carlos (2001, p. 40 e 44 ) a tradução mais correta de "usager" seria usador, definindo um sentido amplo do termo e mostrando uma relação espacial mais ligada ao valor de uso; já o usuário teria uma relação mais restrita ao valor de troca do espaço. Contudo, preferimos utilizar o termo usuário, com as ressalvas expostas anteriormente e assumindo o seu sentido amplo, porque nas traduções de outros autores utilizados prevalece esse termo.

10 É importante destacar que a apropriação relacionada ao uso dos espaços públicos também apresenta o que podemos chamar de uma dimensão restrita, ou seja, quando a apropriação consiste não numa privatização "corporal", mas numa privatização que não permite o uso e a apropriação para os demais usuários, demonstrando atitudes de descaso com a esfera do público, as quais são alimentadas pela concepção de público no senso comum como uma terra de ninguém ou como aquilo que é do governo e do qual é lícito tirar "vantagem". Essa atitude que vem sendo tomada desde tempos coloniais, remetenos às relações clientelistas que caracterizam a formação do Brasil.

11 Entendemos a expressão "salto escalar", num sentido amplo, como relações interescalares e não somente como saltos entre níveis ou degraus estanques.

12 Prost (2001, p. 116) utiliza a expressão "espaços de transição", entre um interior e um exterior, para mostrar essa complementaridade.

13 Parafraseando uma reflexão de David Harvey (1989), reproduzida por Smith (1992), no sentido de que "os movimentos da classe trabalhadora costumam ser melhores na organização e no controle do lugar do que em dominar o espaço" (HARVEY, 1998, p. 216, 


\section{Bibliografia}

BRENNER, Neil. The urban question as a scale question: reflections on Henri Lefebvre, urban theory and the politics of scale. International Journal of Urban and Regional Research. Malden, v. 24, n. 2, p. 361-378, J une 2000.

CALDEIRA, Teresa Pires do Rio. Cidade de Muros: crime, segregação e cidadania em São Paulo. São Paulo: Edusp, 2000.

CARLOS, Ana Fani Alessandri. O lugar no/do espaço. São Paulo: Hucitec, 1996.

Espaço-Tempo na Metrópole: a fragmentação da vida cotidiana. São Paulo: Contexto, 2001.

- Uma leitura sobre a cidade. Cidades, Presidente Prudente, v. 1, n. 1, p. 11-30, jan.jul. 2004.

DE CERTEAU, Michel. A invenção do cotidiano: 1. artes de fazer. 9. ed. Petrópolis: Vozes, 2003. [L'invention du quotidien. 1a. arts de faire, 1990]

GUIMARÃES, Raul Borges. Atores políticos, representação social e produção da escala geográfica. In: MELO, Jayro Gonçalves (Org.). Espiral do espaço. Presidente Prudente: GASPERR, 2003. p. 7-21.

HARVEY, David. Condição pós-moderna: uma pesquisa sobre as origens da mudança cultural. 7. ed. São Paulo: Loyola, 1998. p. 216. [The Condition of Postmodernity: An Enquiry into the Origins of Cultural Change, 1989]

. Espacios de esperanza. Madrid: Akal, 2003. [Spaces of Hope, 2000]

LEFEBVRE, Henri. El derecho a la ciudad. 2. ed. Barcelona: Península, 1973. [Le droit à la ville, 1968].

. De lo rural a lo urbano. 3. ed. Barcelona: Península, 1975. [Du rural à l'urbain, 1970]

. Espacio y política: el derecho a la ciudad II. Barcelona: Península, 1976. [Espace et politique. Le droit à la ville, II, 1972]

De l'État. (4 volumes). Paris: Union Générale d'Éditions, 1976-1978.
Paulo: Ática, 1991. [La vie quotidienne dans le monde moderne, 1968]

The production of space. Oxford: Blackwêll, 1992. [Production de I'espace, 1974]

. A cidade do capital. Rio de Janeiro: DP\&A, 1999a. [Le penseé marxiste et la ville, 1972]

- A revolução urbana. Belo Horizonte: ŪFMG, 1999b. [La révolution urbaine, 1970]

MARTINS, J osé de Souza. O cativeiro da terra. 2. ed. São Paulo: LECH, 1981.

o poder do atraso: ensaios de sociologia da história lenta. São Paulo: Hucitec, 1994.

As hesitações do moderno e as contrāições da modernidade no Brasil. In: - A sociabilidade do homem simples: cotidiano e historia na modernidade anômala. São Paulo: Hucitec, 2000. p. 17-54.

MAYOL, Pierre. O bairro. In: DE CERTEAU, Michel; GIARD, Luce; A invenção do cotidiano: 2. morar, cozinhar. 4. ed. Petrópolis: Vozes, 2002. p. 37-45 [L'invention du quotidien. 2 habiter, cuisiner, 1994]

PROST, Antoine. Fronteiras e espaços do privado. In: _____; VICENT, Gerard (Org.). História da vida privada, 5: da Primeira Guerra a nossos dias. 7. ed. São Paulo: Companhia das Letras, 2001. p. 13-154. [Histoire de la vie privée, vol. 5: De la Primière Guerre Mondiale à nos jours, 1997]

SANTOS, Milton. A natureza do espaço: técnica e tempo, razão e emoção. 2. ed. São Paulo: Hucitec, 1997.

SEABRA, Odette Carvalho de Lima. Territórios do uso: cotidiano e modo de vida. Cidades, Presidente Prudente, v. 1, n. 2, p. 181-206, jul.dez. 2004.

SENNETT, Richard. El declive del hombre público. Barcelona: Península, 1978. [1974] 
SEVCENKO, Nicolau. Introdução: o prelúdio republicano, astúcias da ordem e ilusões do progresso. In: NOVAIS, Fernando A.;

(Org. ). História da vida privada no Brasil (Volume 3: República: da Belle Époque à Era do Rádio). $5^{\text {a }}$ reimpressão. São Paulo: Companhia das Letras, 2002 [1998]. p. 7-48.

SMITH, Neil. Desenvolvimento desigual: natureza, capital e a produção de espaço. Rio de Janeiro: Bertrand Brasil, 1988. [Uneven Development, 1984]

Geography, difference and the politics of scale. In: DOHERTY, J.; GRAHAM, E.; MALEK, M. (Eds.). Postmodernism and the social science. London: Macmillan, 1992 (Texto traduzido ao espanhol por María Franco García e disponível em: <www2.unesp.br/cemosi/vínculos/ trNeilSmith.htm>. Acesso em: 17 jul. 2004)
_-_-_- Contornos de uma política espacializada: veículos dos sem-teto e produção da escala geográfica. In: ARANTES, Antonio (Org.). O espaço da diferença. Campinas: Papirus, 2000. p. 132-159.

SOBARZO, Oscar; SPOSITO, Maria Encarnação Beltrão. Urbanizaciones cerradas: reflexiones y desafíos. Ciudades, Puebla (México), Red Nacional de Investigación Urbana, n. 59, p. 3743, jul.-sept. 2003.

SPOSITO, Maria Encarnação Beltrão. O chão em pedaços: urbanização, economia e cidades no Estado de São Paulo. 2004. 508 p. Tese (Livre Docência) - Faculdade de Ciências e Tecnologia, Universidade Estadual Paulista, Presidente Prudente. 
